\title{
THE PROBLEM OF RECURRENCE IN THE NEW CRIMINAL CODE AND THE IMPACT OF THE NEW CHANGES TO CRIMINOGEN PHENOMENON IN OUR COUNTRY
}

\author{
Vasile STOICA \\ “Dunarea de Jos" University, Galați, Romania \\ stoicabasil30@yahoo.com
}

\begin{abstract}
The present paper wants to emphasize the impact of the new amendments to the penal code in the magazine on the criminogenic phenomenon. The provisions of the new Criminal Code for Romanian recurrence brings new elements in both the definition of its terms and in terms of the punishment.
\end{abstract}

Keywords: recurrence, impact, criminogenic phenomenon the new Criminal Code, recidivism

\section{Introduction}

Entry into force of Law no.286/2009 on the Criminal Code, by means of Law no. 187/2012 for the implementation of Law no.286/2009 on the Criminal Code marked the modification of certain institutions of criminal law among which the condition relating to the plurality of crimes.

As part of the continuous displacement of offenses, recurrence has brought new elements both in terms of the definition and the terms thereof and as regards the penalty applicable in such a situation.

As regards the temporary nature, it is highlighted in even to the definition of this form of plurality and crimes. There have also been reared within the time limits by changing the positive terminal in order to qualify as the offender only on that person sentenced which has committed a further infringement from a certain degree of social threat.

As far as the treatment of sanctionator, the new law has been simplified, within the meaning of that in the case of postconviction it resorted to dealing with an arithmetic ratio, while in the case of the post-executory recurrence, it adopted legal increase with half of the special limits of punishment.

By checking the conceptual acceptance, it has been showed that the, from the point of view of etymological plan, the term "recurrence of the problem comes from the Latin meaning "recidivus"[1], 1or from the Latin verb "recidere"[2], which means "recadere i.e." who commits the same mistake or which falls on the same mistake". In other words, recurrence means committed the offenses, i.e. "repeating the phenomenon after the disappearance of the apparent"[3].

Analysis and the study made on the occasion of the research and development of this work me to define the recurrence of as "a form of continuous displacement of offenses, which consists in committing again of offenses by a person who was sentenced definitively for another crime"[4].

The specialized literature has consistently held several criteria for the classification of this paper, criteria against which have been defined and to the different forms or 
conditions of it. It is important to know these ways because, recurrence always appears under one of those forms and therefore the only way it can appreciate the persistence of the offender, manner of penalty and the design of the legislature with regard to the structure and the conditions governing the existence of a magazine.

In the new approach the penal code, recurrence means that the form of continuous displacement of offenses which consists of commitment with intent or by a person, after having been sentenced to imprisonment penalty of more than one year and up to rehabilitate or until expiration of the rehabilitation, again, of offenses for which the law provides for a lighter penalty with imprisonment of one year or more than one year including detention for life.

The truth of new also provides the fact that at the status of recurrence of account shall also be taken of the judgment of the Court of pronounced abroad, if the deed is provided by the penal law Romanian, only if such determination has been recognized in accordance with the law.

\section{Means of recurrence in the new Criminal Code}

From the definition of the data of the lawmaker in the content of the articles 41 from the new Criminal Code can be noted that it has understood to the distinction between the recurrence of the high and low recurrence, covering a single form of the recurrence of similar to the recurrence of the problem. In this context, the new provisions identify new elements both in terms of the definition of the shops, of its terms as well as in respect of punishment.

The new Criminal code has adopted such general system shops, temporary relative, and international. Although no longer expressly regulated recurrence postconviction and post-executory, the new provisions of the Criminal Code provides for the legal conditions of the shops after the condemnation and of the shops after implementation as well as the regime and criminal law of them.

In the law on the Criminal Code do not result in which was the reason the legislature to waive the distinction between small and great recurrence in the context in which the small recurrence was an effective means of punishment of a murderer which has a degree of social threat because of the repeatability of the facts complained, even if the punishment for these were of less than one year.

In accordance with the provisions of Article 41 from the new criminal Code entitled "Recurrence", is mentioned the following: " There is a recurrence of the problem when, after the naive of a judgment of the court of the imprisonment penalty of more than one year and up to the rehabilitation or expiration of the rehabilitation committed the condemned again to crimes with closer look but with closer look exceeded, for which the law provides for the imprisonment penalty of one year or greater.

There is a recurrence of the problem and in the event that one of the punishment referred to in paragraph 1 is detention for life.

In order to member the status of recurrence is sofer into account and by the judgment of sentence pronounced in abroad, for a deed prescribed by the penal law Romanian, if the judgment by the used conviction and recognized as according to the law".

After the first analysis of a specific text referred to above, resulting in a simplification of the rules in front of the old provisions by Apple the number of forms of the recurrence of the provided for by law, the new text only incriminating postconviction recurrence post-executory, and the national and international without making a distinction between the recurrence of the high and low recurrence.

It is observed at the same time the change of the conditions relating to the terms of the shops that grow basis from 6 months to one year or imprisonment for life as regards concrete penalty laid down by the court for the first period, while for the second period, 
the penalty provided by the law should be prison more than one year or detention for life as well as in the truth of the old.

At first sight the new recriminations creates a more favorable arrangements for those who have been sentenced to punishment of less than one year, although the intention of the legislature has been aggravation sanctionator regime of the shops, by the increase in the duration of the imprisonment penalty which may constitute the first term of the shops to a year.

This encourages the creation by the new provisions seems to be numbering in the context in which the "Evolution of statistics relating to the number of welfare with a criminal record which reproduces the behavior of the Criminal activity"[5], is on the rise.

Increase in the first term of magazine at the jail more than one year or detention for life does nothing but to focus activities and even to encourage the recurrence of the problem on the people sentenced to prison sentences of less than one year, a fact that is not justified in relation to the prevention imperative general and of rated recidivism.

The conditions imposed by the new rules for the existence of the magazine are:

- Final sentence to a penalty of a certain length of time for an offense;

- Committing a new offenses of a certain level intentionally or with the intention exceeded;

- Both condemnation and further infringement to look the same person who plays a central role for the connection between the two terms of the magazine.

\section{Post-conviction Recurrence}

This type of recurrence of the problem exists when, after the final sentence, person commits a new criminal offense. Require such to be met, for the existence of the first term of post-conviction recurrence, the following conditions:

- to be at least one final punishment with imprisonment of more than one year or imprisonment for life;
- judgment of sentence to have been delivered by a Romanian court or from abroad for an offense has been committed with intent or with intent exceeded, in the case of the taken abroad, only if the judgment of sentence has been recognized as according to the law;

- judgment of sentence does not form part of the category of the exempted by law.

Unlike the old, the truth of the current Penal Code provides only three cases of convictions which do not lead to the condition of the recurrence of namely:

1. when the facts are no longer provided for in the law on the criminal proceedings;

2. for offenses amnistiate;

3 . in the case of crimes committed through of manslaughter.

As regards the second term of postconviction recurrence, it must meet the following conditions:

- the new deed to have been committed with intent or intent exceeded, subsequently definitive condemnation, irrespective of the nature of her. The form of the new crimes committed through can be consumed or remaining in the phase of attempted and the quality of can be both by the author and the instigator or accomplice. May constitute a second deadline of the magazine both committing a single crimes and more;

- to the new offense the law must provide for a jail penalty of more than one year or even imprisonment for life. The purpose of this condition is the restriction of the area of attracting the status of the recurrence of only of the offenses more serious; the

- offense to have been committed after the naive to the conviction decision, before the execution of the punishment, during the execution of the punishment or in the weak. Through this feature postconviction recurrence can be distinguished from post-executory recurrence. 


\section{Post-executory Recurrence}

Is that type of recurrence of which exists when, after the condemned has been carried out in the entire punishment prior to or after the prescription of the penalty execution or the decree untied committed a new, criminal offense. Recurrence postexecutory is subject to Article 41 paragraphs 1 and 2 from the new criminal Code according to which "when after the execution of a punishment with imprisonment of more than one year and up to rehabilitate or expiration of the rehabilitation committed the condemned again a crime with intent or with intent exceeded, for which the law provides for the imprisonment penalty of one year or higher". Require such to be met, for the existence of the first term of post-executory recurrence, the following conditions:

- minor should be executed in the entire punishment that has been the subject of the first convictions or it is to be regarded as and performed, the penalty which has been more than one year or imprisonment for life. Does not submit the relevant method of carrying out the death penalty, it can take place "under detention, in liberty, with the execution of sentence at the place of work, etc.".[6] Also, the first term of the magazine postexecutory may also consist in a punishment that was pardoned wholly or partly or for which the limitation period for the enforcement of the penalty execution has been accomplished, how will may also consist of the prescription of the penalty;

- deed for which it has carried out the punishment to have been committed with intent or with intent exceeded;

- penalty performed or considered as carried out not to be part of the sentence which does not involve the condition of relapse.

As regards the second term of postexecutory magazine, it must meet the following conditions:
- for the new criminal offense, the law to provide for a jail penalty of one year, more than one year or imprisonment for life;

- to the new offense the law must provide for a jail penalty of more than one year or even imprisonment for life;

- the date of the commitment of the new offenses may be after the date of the penalty execution, after the publication of the decree ordering total or of the rest of the punishment, or after the date on which the limitation period for the enforcement of the penalty execution prior to be realized.

\section{International Recurrence}

Represents the situation when the first term of the magazine is a judgment of sentence pronounced abroad.

Thus, the international recurrence has the following characteristics:

- is binding because the law stipulates that in establishing the status of recurrence is taken into account and by the condemnation pronounced abroad, than the old provision which a bonus to the optional;

- is double incrimination, whereas the deed for which it has delivered a condemnation abroad must have a correspondent in the legislation of our country. Thus, the text of the law makes the taking into account of condemnation taken abroad by the fact that it should be laid down as criminal offenses and the National Romanian and such determination must be acknowledged by the Romanian court;

- judgment of sentence pronounced abroad is recognized by a court in our country. „The Recognition could be made on the accuracy with which path in the framework of a criminal trial in progress or on the way home by the court seized in this end"[7].

6. The impact of recurrence on the criminogenic phenomenon 
In criminological acception, the concept of recurrence of committing new offenses, even if the persons concerned have or have not been issued by the presence or not of keeping records of criminal proceedings, of responsibility or criminal punishment, the time elapsed since the committing of criminal offenses, etc. Is relevant if the offense was the previous known by the authorities and if it has been the subject of a reaction to the appropriate legal.

Among criminologists to accept such an idea whereas they have to explain not only the criminal conduct of the individuals but also the cause of her recurrence, in so far as the conduct of the previous criminal has been the relevance and has drawn on the way the consequence of the measures provided for by law.

The typology of recidivist convicts plays a particularly important role in the assessment of the crime status recidivist convicts, the criminological theory the following types of recidivists: antisocial recidivists, situational recidivists and asocial recidivists.

\section{Conclusions}

New rules relating to the recurrence of the emphasizes the fact that the legislature has given up on the distinction between the recurrence of the high and low recurrence incriminating one single form of recurrence of the closest to the recurrence of the sea from the old penal code.
In respect of post-convictional recurrence the new Criminal Code establishes that the first time the existence of a final judgment of the court of the imprisonment penalty of more than one year as compared to the 6 months in the old grief. At the second period shall be one year or greater than the truth of old where the punishment had to be only of more than one year.

Sanctionator regime in the case of the magazine is established in the form of arithmetic overlapping of the penalties laid down in relation to the old penal code which made reference to legal the cumulating provided for in the case of the contest of crimes with the possibility of applying a current of punishment.

In conclusion, the addition to the old regulatory authorities consider that the new regulations in the magazine is aimed at the application of a sanctionator worsened the person committing crimes with a degree of social threat raised, paying at the perverseness of those who a person committing crimes with a degree of social threat reduced through the inclusion of the latter under the supervision of this institution. After the entry into force of the new Penal Code can be noticed a decrease in the number recidivist convicts which strengthens the belief of the legislature that the amendments made in terms of recurrence of the slowly, slowly attain their purpose.

\section{References}

[1] Cocaina A., Recurrence in criminal law, edition reviewed and added, Publishing house LUMINA LEX, Bucharest, 1995, p.24

[2] Buzea N.,., Criminal offense and culpability, Alba Iulia, 1944, p.715

[3] Mateut Ghe., Recurrence in theory and criminal practice of Law, Publishing house LUMINA LEX, Bucharest, 1997, p.51

[4] Bulai C., Manual of criminal law. The general part, Volume II, All Publishing House, Bucharest, 1997, p.226

[5] Pasca V., Regulation of the paper in the Criminal Law. The "Law", no.9/2010, p.13

[6] Boroi Al Criminal law. The general part. Under the new Criminal Code, Publishing House C.H.Beck, Bucharest, 2010, p.231

[7] Pavaleanu V.,Procedural Criminal Law, Volume II, Publishing House Lumina Lex, Bucharest, 2004, p.540 